\title{
SISTEM INFORMASI PRAKTEK KERJA INDUSTRI PADA SMK ISLAM SIRAJUL HUDA PAOK DANDAK
}

\author{
Abdul Gani ${ }^{1}$, Wire Bagye ${ }^{2}$, \\ ${ }^{1}$,Sistem Informasi, STMIK Lombok \\ 1,Teknik Informatika, STMIK Lombok
}

Jln. Basuki Rahmat No.105 Praya Lombok Tengah 83511 Lombok Tengah Telp.(0370) 654310

1 gansahreza@yahoo.com, ${ }^{2}$ wirestmik@gmail.com.

\begin{abstract}
The data management of students who are carrying out industrial work practices at SMK Islam Sirajul Huda Paok Dandak still in the form of printed documents. In the delivery of information is still on the announcement so that the information can be lost or torn. Information obtained by the Student through the mentor teacher. At the time of the visit to the prakerin location the supervising teacher convey information from the school. This causes the information obtained by students delayed for one month. Information should be received directly by the students when the informs is issued by the prakerin activities committee. In this research developed system of web-based isiting by mentor is moutthly industry-based business information information system of SMK Sirajul Huda Paok Dandak. Analysis method using PIECES method, Design method using Unifed Modeling Language (UML), interface design using CSS, Javascript, Dreamweaver, and xampp as database server. This information system provides information to students of industry practice participants about the format of Prakerin's activity report, visitation schedule of supervising teacher, and timing information on the end of Prakerin's activities. The results of this study indicate the system of technical internship information technology SMK Sirajul Huda provide ease in the delivery of information to students field work practice participants. Information is delivered to 80 percen students in less than a week. 20 percent of those who are not informed are students who do not access the web of the technical internship information system.
\end{abstract}

Keywords : SMK, industrial work practices,

\begin{abstract}
Abstrak
Pengelolaan data siswa yang sedang melaksanakan praktik kerja industri di SMK Islam Sirajul Huda Paok Dandak masih dalam bentuk dokumen cetak. Dalam penyampaian informasi masih file cetak dan ditempel dipapan pengumuman sehingga informasi dapat hilang atau sobek. Informasi yang diperoleh Siswa melalui guru pembimbing. Pada saat melakukan kunjungan ke lokasi prakerin guru pembimbing menyampaiak informasi dari sekolah. Jika kunjungan dilakukan satu kalisatu bulan maka informasi yang diterima siswa sekali dalam satu bulan. Pada penelitian ini dikembangkan system informasi praktek kerja industri berbasis web SMK Sirajul Huda Paok Dandak. Metode analisis menggunakan metode PIECES, Metode perancangan menggunakan Unifed Modeling Language (UML), desain interface menggunakan CSS, Javascript, Dreamweaver, dan Exampp sebagai database server. System informasi ini memberikan informasi kepada siswa peserta praktek kerja industry tentang format laporan kegiatan Prakerin, jadwal kunjungan guru pembimbing, dan informasi waktu berakhir kegiatan Prakerin. Hasil penelitian ini menunjukkan system informasi praktek kerja industri SMK Sirajul Huda memberikan kemudahan dalam penyampaian informasi kepada siswa peserta praktek kerja Industri. Informasi tersampaiakan kepada 80 percen siswa dalam waktu kurang dari satu minggu. 20 percen yang tidak mendapatkan informasi merupakan siswa yang tidak mengakses web sisitem informasi praktek kerja Industri.
\end{abstract}

Kata Kunci: Sistem Informasi, Praktik Kerja Industri, Web, PIECES, UML. 


\section{Pendahuluan}

Pengelolaan data siswa yang sedang melaksanakan praktik kerja industri di SMK Islam Sirajul Huda Paok Dandak masih dalam bentuk dokumen cetak. Dalam penyampaian informasi masih file cetak dan ditempel dipapan pengumuman sehingga informasi dapat hilang atau sobek. Informasi yang diperoleh Siswa melalui guru pembimbing. Pada saat melakukan kunjungan ke lokasi prakerin guru pembimbing menyampaiak informasi dari sekolah. Jika kunjungan dilakukan satu kalisatu bulan maka informasi yang diterima siswa sekali dalam satu bulan.

Dengan sistem ini maka siswa akan mengalami keterlambatan dalam mengerjakan laporan kegiatan praktek kerja industri dan kegiatan terkait lainnya. Hal ini akan berdampak terhadap waktu penyelesaian kegiata semakin panjang.

\section{Tinjuan Pustaka}

Sistem informasi praktik kerja industri di SMK Negeri 3 Kasihan Bantul (SMSR Yogyakarta) dikembangkan menggunakan framework Codeigniter dengan model pengembangan Waterfall yang terdiri dari Analisis kebutuhan, Desain Sistem, Implementasi Sistem, dan Pengujian/Test Sistem. Sistem ini memiliki tiga pengguna yaitu admin/koordinator prakerin, guru pembimbing, dan siswa dengan fitur sesuai dengan hak akses yang dimiliki, akan tetapi sistem tidak mengikut sertakan perusahaan dalam mengakses system (Kurniawan,2015).

Sistem yang dikembangkan berfokus pada instansi/perusahaan sedangkan analisa dan perancangan pada penelitian ini mencakup pendaftaran, jadwal, kuota, peserta $\mathrm{PKL}$, antrian serta penilaian PKL. Akan tetapi tidak mengikut sertakan mahasiswa sebagai pelaku PKL untuk mengakses sistem guna sebai media untuk memberikan keluhan terhadap proses PKL (Arifin,2014).

perancangan sistem informasi manajemen praktek kerja Industri berbasis web menggunakan YUI Library menghasilkan sistem yang dapat mempermudah dalam pengelolaan PKL dalam membuat id-card, rekap absensi, rekap data PKL, dan pembuatan surat balasan otomatis. Sistem dikembangkan menggunakan metode pengembangan waterfall. Akan tetapi rekap nilai masih manual (Chandra dkk,2013).
Rancang bangun sistem informasi praktik kerja industri berbasis web (studi kasus: SMK Al-Azhar Menganti Gresik) menunjukkan bahwa program dapat menghasilkan sistem yang mampu mengolah dan menyediakan informasi mengenai praktik kerja industri kepada administrator sekolah dan dapat menampilkan evaluasi penilaian hasil praktek kerja industri untuk pihak sekolah dalam memonitoring perkembangan peserta didik selama program prakerin berlangsung dari tahun ke tahun (Ningsih,2012).

sistem informasi yang dapat mempermudah mahasiswa dalam melakukan pendaftaran mata kuliah tugas akhir dan praktek kerja Industri di lingkungan program studi teknik informatika Undip dan mempermudah koordinator TA dan PKL dalam melakukan administrasi. Sistem yang dikembangkan bersifat Objek Oriented Programing (OOP) dan menggunakan metode unified process (Ryan dkk,2012)

\section{Metodologi Penelitian}

\subsection{Metode Pengumpulan Data}

1. Observasi

Mengadakan pengamatan secara langsung pada SMK Sirajul Huda Paok Dandaj hal yang dianggap penting untuk mendapatkan model penyampian informasi, pihak pihak yang terlibat, kebutuhan informasi, keluhan dan harapan.

\section{Wawancara}

Melakukan tanya jawab kepada panitia Praktek Kerja industry, siswa, dan pihak industry.

\section{Studi Pustaka}

Mempelajari teori-teori baik dari buku-buku, jurnal dan internet yang berhubungan dengan tema penelitian.

\subsection{Metode Analisis}

Pada penelitian ini menggunakan metode analaisis PIECES.

\subsection{Metode Perancangan}

Metode perancangan yang digunakan adalah metode Unifed Modeing Laguage(UML)dengan tahapan-tahaan perencanaan, analisa, desain, implementasi, pengujian dan pemeliharaan.

\subsection{Metode Pengembangan}

Pengembangan system informasi praktek kerja industry ini dikembangkan dengan metode SDLC dengan enam tahap pengembangan. 


\subsection{Metode Pengujian Sistem}

Pengujian menggunakan metode black box dengan menguji prosedur perancangan yang terdiri dari input, proses, dan output sistem informasi praktek Kerja Indutri.

\section{Hasil dan Pembahasan}

System informasi praktik kerja industri memiliki empat aktor yaitu admin selaku koordinator, guru pembimbing, siswa dan perusahaan. Admin atau koordinator dapat mengelola data pengguna seperti guru pembimbing, siswa, dan admin sendiri, serta mengelola informasi, mengelola industri, mengelola penempatan, mengelola nilai. Guru pembimbing dapat mengelola nilai, melihat daftar siswa bimbingannya,mengelola profil, mengelola data bimbingan dengan login terlebih dahulu. Siswa dapat mengelola profil, mengelola industri, melihat nilai/hasil prakerin, dan mengelola bimbingan dengan login terlebih dahulu. Perusahaan dapat mengoah data absensi dengan login terlebih dahulu.

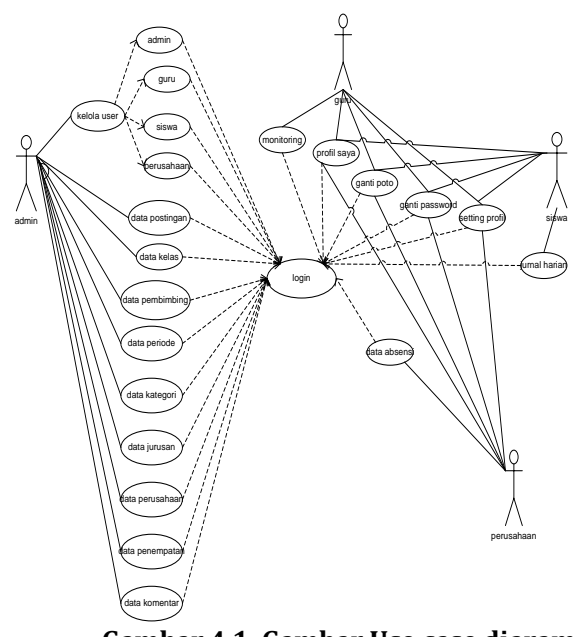

Gambar 4.1. Gambar Use case diaram

Admin merupakan aktor yang memiliki hak akses secara keseluruhan. Dalam sistem ini yang di maksud dengan admin adalah koordinator praktik kerja industri. Admin dapat mengelolan data pengguna, mengelola informasi, mengelola industri, penempatan, nilai, dengan login terlebih dahulu. Admin dapat menambah, mengubah, menghapus data, upload data, dan download data.

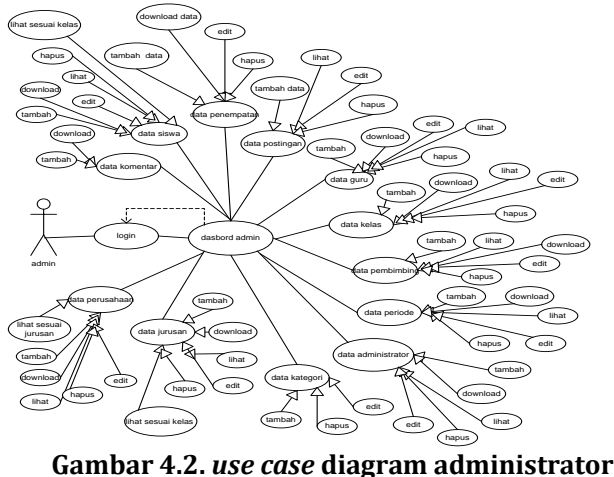

Siswa merupakan aktor yang dapat memasukkan tempat industri, merubah profil, melihat status prakerin, menambah data bimbingan, dan melihat nilai hasil prakerin.

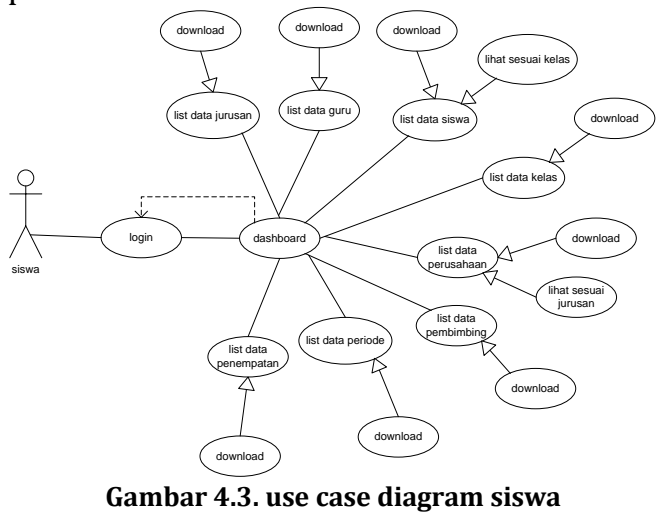

Pada menu about terdapat dua menu drop down yaitu develover atau menu untuk menampilkan info tentang pembangun dari sistem ini dan menu SMK Islam Sirajul Huda Paok dandak menampilkan informasi tentang SMK Islam Sirajul Huda Paok Dandak. Menu contact memuat tentang keluhan-keluhan selama dalam proses prakerin berlansung yang di tujukan kepada guru pembimbing prakerin. Menu galeri, menampilkan photo-photo kegitan. Menu jurusan, terdapat dua menu drop down di dalamnya yaitu jurusan multimedia dan jurusan agrobisnis. Menu other, didalamnya terdapat 4 menu drop down, yaitu menu buku tamu, bursa kerja, prestasi sekolah, dan menu teaching factory. Menu login digunakan oleh admin, guru, dan Siswa. 


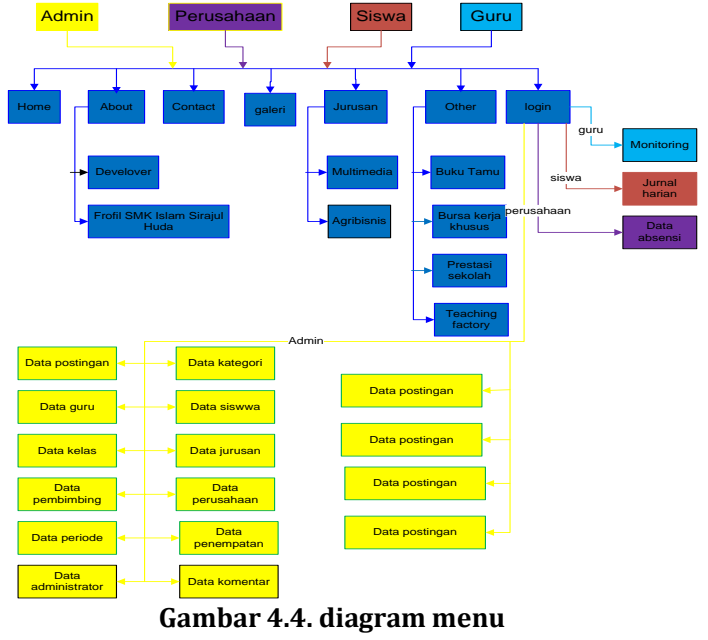

Penelitian ini menghasilkan aplikasi berbasis web sebagai media informasi kepada siswa yang sedang menempuh kegiatan Praktek kerja Industri.

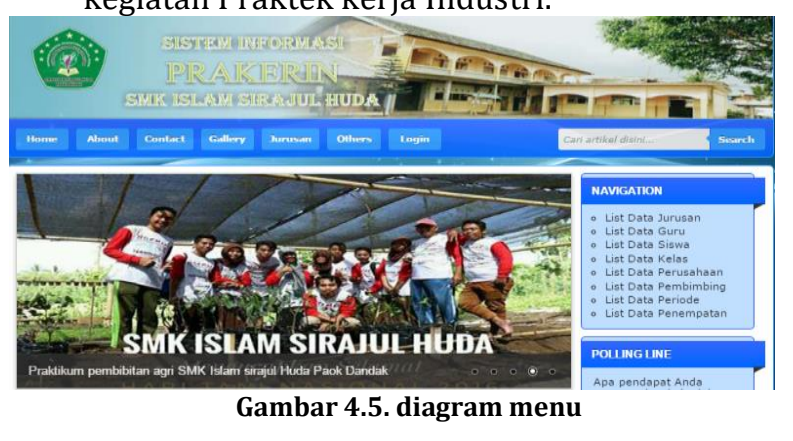

Halaman utama menampilkan artikel, berita maupun informasi-informasi tentang semua kegiatan yang ada di SMK Islam Sirajul Huda Paok Dandak, baik yang formal, maupun non formal.

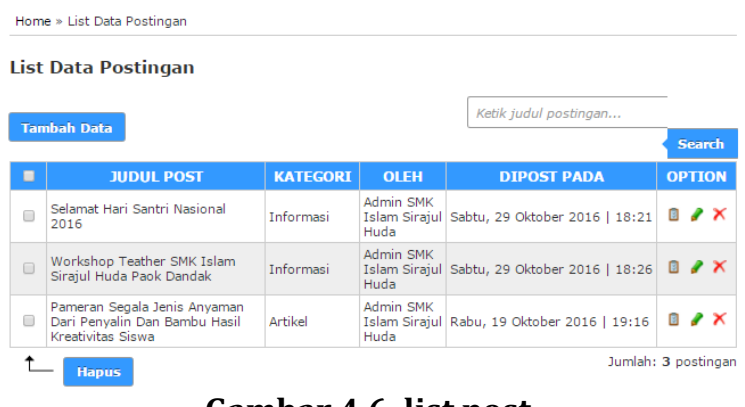

Gambar 4.6. list post

Halaman list data postingan menampilkan kegiatan-kegiatan yang di lakukan oleh siswa maupun guru yang dapat di posting di sistem, baik dalam kategori informasi, artikl, maupun berita.

\section{Kesimpulan dan saran}

Performa system lama siswa harus mengunjungi madding sekolah untuk mendaatakan informasi sehingga siswa yang melaksanakan prakerin dilokasi yang jauh darii sekolah sulit untuk menapatkan informasi. Dibutuhkan system yang dapat memberikan informasi yang dapat diakses oleh siswa dengan relative mudah sehingga sisiwa tidak harus datang ke sekolah untuk medapatkan informasi. Dari segi ekonomi system lama membuthkan pengeluaran setiap tahun dan setiap informasi baru akan diterbitkan. Biaya ini termasuk biaya cetak dan pembelian erangkat baru setiap pelaksanaan prakerin. Dengan membangun aplikasi web maka biaya dikeluar hanya intuk pembuatan web dan hosting tahunan yang lebih murah dibandingkan dengan membuat dokumen cetak. Control pada system konvensional hamper tidak dapat dilakukan karena bersifa dokumen cetak.

Sistem ini memberikan informasi mengenai Praktek Kerja Industri secara online bagi siswa yang prakerin dan pembimbing prakerin serta pengguna lain yang ingin mengetahui web ini. Pada proses pengajuan praktek kerja industri, siswa harus melewati beberapa tahap. Setelah siswa melengkapi tahap-tahap pendaftaran berikutnya sistem informasi prakerin yang akan bekerja. Dimana kegiatan pencatatan data-data prakerin akan dilakukan oleh administrasi prakerin yang nantinya data tersebut akan dikirim dan disimpan pada web.

Penelitian selanjutnya dapat dikembangkan sistem informasi Praktek Kerja Industri berbasis android atau di akses dan dikelola melalui perangkat berbasis flatform Android.

\section{Daftar Pustaka:}

[1] Arini, D. (2011). Pengaruh Prestasi Praktik Kerja Industri dan Pengetahuan Kewirausahaan Terhadap Minat Berwirausaha Siswa Kelas 3 Teknik Bangunan SMK Negeri 2 Pengasih Tahun Ajaran 2010/2011. 11.

[2] Brian Dobing and Jeffery Parsons. (2006, May). How UML Is Used. Communication of th ACM, 49, 109.

[3] Pressman, R. S. (2012). Rekayasa Perangkat Lunak - Buku Dua, Pendekatan Praktis (Edisi 7). Andi 
[4] Wardana. (2010). Menjadi Master PHP dengan Framework Codeigniter. Jakarta: PT. Elek Media Komputindo.

[5] Al-Fedaghi, S. (2011). Developing Web Applications. International Journal of Software Engineering and Its Applications, 5.

[6] Chandra K, F., J.Gundo, A., \& Somya, R. (2013). Perancangan dan Implementasi Sistem Informasi Manajemen Praktek Kerja Lapangan Berbasis Web Menggunakan YUI Library (Studi Kasus : PT.PLN (Persero) P3B Jawa Bali APP Salatiga). Jurnal Teknologi Informasi-Aiti, 101-200.

[7] Haviluddin. (2011, Februari 1). Memahami Penggunaan UML ( Unified Modelling Language). Jurnal Informatika Mulawarman, 6, 9.
[8] Ningsih, P. W. (2012). Rancang Bangun Sistem Informasi Praktek Kerja Industri Berbasis Web (Studi Kasus: SMK ALAZHAR MENGANTI GRESIK).

[9] Turban, E., Rainer R.Kelly, J., \& Potter Richard, E. (2006). Introduction to information Technology, 3th ed. Jakarta: Salemba Infotek.

[10]Kurniawan(2015). Analisa dan pengembangan sistem informasi praktik kerja industri berbasis website di SMK Negeri 3 Kasihan Bantul, di kembangkan dengan menggunakan framework codeigniter, dengan model pengembangan waterfall.

[11]Arifin(2014). Analisa dan perancangan sistem informasi praktek kerja lapangan pada instansi/lapangan, metode observasi, studi pustaka, dan interview. 